\title{
Focusing Organizational Culture and Employees' Citizenship Behaviour Narratives on Broadcasting Organizations in Nigeria
}

\author{
Eromafuru, Edward, Godbless ${ }^{\circledR}$ \\ Aigbomian, Sunny Ewan² (D)
}

'Department of Business Administration, Delta State University Abraka, Nigeria. Email:eeromafuru@yahoo.com

${ }^{\circ}$ Department of Business Administration, School of Business Studies, Edo State Polytechnics, Benin City, Nigeria.

Email:saigbomian@yahoo.com

\begin{abstract}
The study was undertaken with a view to exploring if the dimensions of organizational culture predict the citizenship' behavior of employees in the Nigerian Broadcasting Organisations. Documented evidences have revealed that not much work have been carried out in this area to fully capture and address the real essence of the culture of an organization in relation to citizenship behavior of employees in Nigerian. For the first time in the history of the Nigerian communication industry, both private and public broadcast organizations were combined and the study was interested in analyzing how the benefits that spur from the figurative marriage between organizational culture and employees' citizenship behavior can be adapted to the Nigerian Broadcast Organisations 'needs. The cross-sectional research design through survey method and the inferential static of multi-variate regression were employed to conduct this research at $95 \%$ confidence level. The study, heavily anchored on the social exchange theory to explain the linkage between organization culture's dimensions and employees' citizenship behavior' measures, has affirmed significant positive relationship among the intervening variables which are that: "the organizational culture' dimensions significantly predict employees' citizenship behavior' measures; and the dimensions of organizational culture with the exception of risk tolerance are seen to significantly predict employees' courtesy in the Broadcast organizations". It is concluded that to forge cohesion and secure employees' undiluted commitment to missions and goals, management must sustain an ideal structure that integrate the needs of both the employees and those of the organization.
\end{abstract}

Key words: Organization culture, Citizenship behavior, Broadcast Organization, Nigeria.

Citation | Eromafuru, Edward, Godbless; Aigbomian, Sunny Ewan (2020). Focusing Organizational Culture and Employees' Citizenship Behaviour Narratives on Broadcasting Organizations in Nigeria. Asian Journal of Social Sciences and Management Studies, 7(1): 71-79.

History:

Received: 24 January 2020

Revised: 4 March 2020

Accepted: 6 April 2020

Published: 28 April 2020

Licensed: This work is licensed under a Creative Commons

Attribution 3.0 License (cc) E

Publisher: Asian Online Journal Publishing Group
Acknowledgement: Both authors contributed to the conception and design of the study.

Funding: This study received no specific financial support

Competing Interests: The authors declare that they have no conflict of interests.

Transparency: The authors confirm that the manuscript is an honest, Transparency: The authors confirm that the manuscript is an honest,
accurate, and transparent account of the study was reported; that no vital accurate, and transparent account of the study was reported; that no vital
features of the study have been omitted; and that any discrepancies from the features of the study have been omitted;
study as planned have been explained.

Ethical: This study follows all ethical practices during writing.

\section{Contents}

1. Introduction 72

2. Literature Review

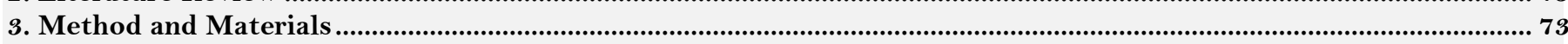

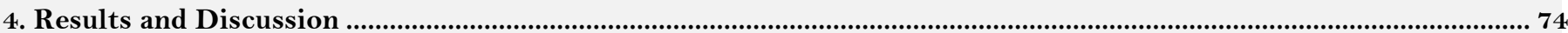

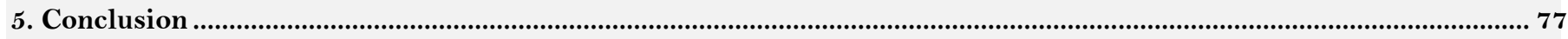

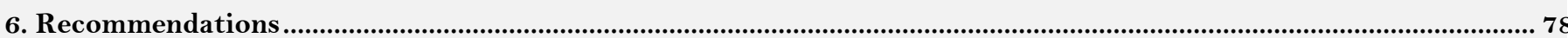

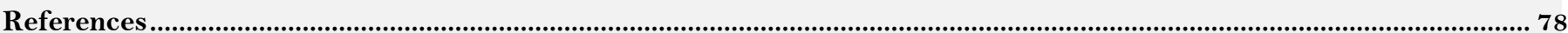




\section{Contribution of this paper to the literature}

The study was undertaken with a view to exploring if the dimensions of organizational culture predict the citizenship' behavior of employees in the Nigerian Broadcasting Organisations.

\section{Introduction}

Among the practical insights and lessons from the Resource Based Theory are that human capital is hard to imitate, rare, valuable, irreplaceable, indefatigable, and socially complex. Under proper climate, organisation can translate investment in its human resources into fleeting investment opportunities, superior product or service offering, shared values, higher productivity, good public image, enhanced job satisfaction, competent building, and competitiveness. Mohanty and Rath (2012) believed that the initiative can be "a unique source of competitive advantage for quite a number of organizations". In the present realities, the way and manner in which the culture of the organization influences employees have been of deep curiosity. One essential area in the field of human capital development is the evolving culture that influences the ways employees and organizations should behave and act (Aslam, 2012). It is held by Beck and Wilson (2000) that ensuring that the duties of an employee through task performance is not the only known means of assessing and appraising employee effectiveness but also includes performance that goes beyond expectations, adjusting, anticipating, and responding to future business dynamics and others. According to Gülsevim (2017) "the recognition of employee is not rocket science but a clear and explicit thing for organizations to always embrace and do in their workplace". Concepts that have evolved in like manner to employees' citizenship behaviour are organizational spontaneity, contextual performance and pro-social behaviour. They have been used interchangeably in various capacities to explain the meaning of the valuable non-task employees' behaviour that exist in organizations (Appelbaum, 2004; Chamdan, 2013; Denison, 2000; Organ \& Ryan, 1995). The evolutionary dynamics of the different concepts to explain employees' behaviour has been with a sustained interest in bringing out the sequential occurrence and the implications of such kinds of behavioral performance in modern organizations. Organ (1997) demonstrated a clear picture of group differences of personality with respect to citizenship behaviour. But in real sense, the usefulness of personality in relation to such anticipated behaviours has been observed in the trait of conscientiousness to be very limited (Shein, 1996). Quite a good number of studies have been done concerning social exchange relation on how employees' engage in beneficial behaviour in order to receive good attention from their organization (Beck \& Wilson, 2000; Gim \& Desa, 2014).

No matter how relevant the social exchange framework may present, there are factors within the organization, like the culture that may function as a basic means for knowing the exact behaviours that are nontask (Guillard \& Neweś, 2010). According to Organ and Ryan (1995) and Denison (2000) only few studies have actually researched these relationships between the culture of the organization and employees' citizenship behaviour. Denison (2000) in his submission provided an explanation on behaviour by saying that cultures encourages, reinforce and elicit key behaviours of employees' which propel the effectiveness of the culture of the organizations. While Khan and Rashid (2012) opined that organizational culture is a system of employees' behavioral pattern that the organization has packaged over time to be able to survive the challenges of internal and external environments.

According to Gim and Desa (2014) the belief that culture energizes employees' behaviour has not adequately been substantiated by empirical review. Hence, this leads to the current debate on the influences of culture on employees' behaviour. Current revelations in the literature on organizational environments suggest the understanding of cultural implication on employees (Kroth \& Peutz, 2011). Gim and Desa (2014) further stressed that the Japanese cultural system of operation in their organizations appears to be the key survival element of Japan in the areas of cohesiveness and commitment. This further explains that culture in organization must be an ingrained component of behavioral pattern of employees' with respect to individual level of achievement to the level of cooperation that exists in the system. These to a large extent are product of rule adherence to innovation within the organization.

Chamdan (2013) examined culture as a system of meaning for the employees who are sensibly making contributory progress towards the organization. In like manner, it is the way the individual and group behave in a unique pattern. According to Hameed, Ramzan, and Zubair (2014) studies that have actually investigated the influence of culture of the organization on employees' citizenship behaviour are scanty and limited in number. Organizational culture comprises elements like symbols, artifacts and values. These elements allow the environment provide the employees with the needed framework of the expectations in the work place. Guillard and Neweś (2010) proposed the concept of role as the major perceptual means of leveraging between the individual and organization. Role distinctions in organizational context ensure the fundamental relationship between employees' behaviour and culture. In theory, it is the framework of social systems that connect the requirements in which the system affect their employees' as individuals. The study of Valentino and Brunelle (2004) on the culture of organization suggests the importance of roles by emphasizing the influences of culture on the individual cognitive processes. This to a great extent energizes the retrieval processes of perceptions that are consistent with the overall organizational cultural values. Thus, they concluded that the various cultures that are prevalent in the different organizations involve unique role understanding and perceptions that subsequently influence the behaviour of employees. The study is hung on the platform that, past organizational efforts to reap the reward that results from strategic management of their human capital have met with abysmal futility; partly due to the non-integrative posture of their cultural platforms or an enshrined defective structure that neither empowers nor supports employees' personal growth and self-worth. Literature is replete with record of frantic efforts made in these areas by concerted researchers and individuals from the industrialized nations of the world but not so much in the case of developing countries where none of such studies has been undertaken. This study fills that void. 


\subsection{Objectives of the Study}

The general objective of this study is to examine organizational culture and employees' citizenship behaviour in broadcast organizations in Delta and Edo States.

The specific objectives are to:

(i) Establish if organizational culture predicts employees' conscientiousness.

(ii) Investigate if organizational culture predicts employees' civic virtue.

(iii) Measure if organizational culture predicts employees' courtesy.

(iv) Appraise if organizational culture predicts employees' sportsmanship.

(v) Find out if organizational culture predicts employees' altruism.

\subsection{Research Hypotheses}

$\mathrm{Ho}_{\mathrm{o}}$ Organizational culture does not significantly predict employees' conscientiousness.

$\mathrm{Ho}_{2}$ Organizational culture does not significantly predict employees' civic virtue.

$\mathrm{Hos}_{\mathrm{s}}$ Organizational culture does not significantly influence employees' courtesy.

$\mathrm{Ho}_{*}$ Organizational culture does not significantly predict employees' sportsmanship.

$\mathrm{Ho}_{\overline{5}}$ Organizational culture does not significantly influence employees' altruism.

\section{Literature Review}

\subsection{Social Exchange Theory}

The study rests on Social Exchange Theory (SET) which explains social behaviour as a product of an exchange process. This theory was introduced by the Sociologist, Homans (1958) but later cited by Erhan and Hatice (2014) in his work "Social Behaviour as Exchange". In effect, the theory is about the social evaluation of human minds and group behaviour at work. The SET explains the process of social change and stability as negotiated exchanges between the parties involved. Implicit in the theory is the notion that the relationships that exist among humans are formed on the basis of personal gain (cost-benefit analysis) and the comparative assessment of the alternatives available. The focus of the exchange process is the expected maximum benefits which revolve around cost minimization principle. Employees on a comparative note try to equate the potential benefits of the process with the risks involved in social relationships (Arabaci, 2010). When the risks exceed the rewards or benefits, employees may choose eventually terminate such relationship. The theory assumes that relationships that guarantee the best returns for the least amount of effort are the ones the individual will value the most. The theory in effect holds the belief that the kinds of relationships social beings create and maintain are the ones that evolve the best rewards and reduce costs (Appelbaum, 2004).

The theory is a complex model in contrast with simple economic model of costs and rewards relationships and covers the three combinatorial factors: cost-benefit analysis, comparison and available alternatives. Erhan and Hatice (2014) opined that individuals involved in the exchange, expresses feelings about the expected returns. This theory further suggests that individuals should assist others. Falemu and Ojo (2013) in the same context explained that the behaviour individual would show comes from a burning desire to get the best expected rewards and reduce costs as much as possible. Costs are issues that are assumed to have negative effects in a relationship. For example, one can spend money, time and putting effort into a relationship. The expectations of the individual are the benefits gotten from such relationship like social support, and others. To effectively and efficiently determine the value of such relationship, the theory prescribed that we take the benefits and minus the costs. Positive relationships in a process exist when the benefits dominate the costs while negative relationships exist when costs are higher than the expected benefits.

Two approaches to social exchange theory are, the social interaction and the relationships approaches. The social interaction approach appraised employees' and the individuals in particular, as rationally engaged to achieve what they need by exchanging their perceived valued resources with others that need it. This idea was corroborated by Erhan and Hatice (2014). Secondly, the relationship approach examines exchange process between groups as a complete whole. The approach has it that when involved in a group that is based on a platform of loyalty, individuals contribute and subsequently get their expected benefits. Previous applications of the social exchange theory emphasized the description of the starting and the ending of social relations in work places, family settings as well as in the area of romantic relationships (Khan \& Rashid, 2012). Present areas of interest of study include the evolvement of fairness in social exchange relations and how it connects to relational satisfaction and dissolution. The utilization and application of authority or power in social relations is based on the control of benefits and costs. The reckless use of such power as well as coalition role is altering the equilibrium of power among actors in the network of individuals or organizations (Mahin \& Mohammad, 2014). With regard to the application to work settings and family environment, the social exchange theory has been applied in diverse organizations and inter-organizational relations contexts. Organizations, in earnest, need various kinds of resources to effectively engage in strategic management. and requires good time. The resource dependence approach in this case shows and emphasizes the strategic application of the social exchange reasoning to the behaviours of organizations and its divisional units, Obinozie (2016).

Interestingly, the emerging focus of economic sociology has started making inference on ideas that emerged from the social exchange theory (Tansley, 2007). This was done to appraise the coming of network of entities and the pattern of power processes that evolved such networks. Network effects on labour practices, informal influence among organizations, the organization of business groups, and the formation of international linkages that cross traditional national boundaries of economic and productive activity are important issues of debate in economic sociology (Tahura \& Mehrali, 2015).

\section{Method and Materials}

The research design for the study was cross-sectional, through survey method. The population of the study consists of 846 employees of Broadcast organizations in Delta and Edo states. Using Yamane (1967) a sample size 
of 282 staff of the organizations was engaged. . Questionnaire was the research instrument employed to collect data. The five-point scale Likert-type question response format was used and were assigned the values: Strongly Agree $(\mathrm{SA})=5$ points; Agree $(\mathrm{A})=4$ point; Undecided $(\mathrm{U})=3$; Disagree $(\mathrm{D})=2$ and Strongly Disagree $(\mathrm{SD})=1$. The reliability assessment was by means of Cronbach's Alpha index tests, which gives above 0.8 coefficients see Table, A1 (Appendix A). Data was analyzed using descriptive statistics including frequency tables, percentages, mean, standard deviation, and standard error of the mean. The inferential statistics of linear regression was used to test the hypotheses, and Stata Version 13.0 software was used to run the data.

\subsection{Model Specification}

Hanging on the general objective of the study, the functional form of relationship between employees' behaviour and organizational culture is:

Employees' citizenship behaviour $=\mathrm{F}$ (Organizational culture)

The regression equation can therefore be stated as:

$$
\mathrm{ECBi}=\mathrm{a}+\mathrm{b} \mathrm{Ci}
$$

Where $\mathrm{ECBi}=$ Employees' citizenship behaviour (dependent variable)

\section{$\mathrm{OC}=$ Organizational culture (independent variable)}

Measures of the dependent variables are: conscientiousness, civic virtue, courtesy, sportsmanship, and altruism.

Similarly, the independent variable is measured by: individual responsibility, individual autonomy, conflict tolerance, risk tolerance, support, structure; and belief \& norms.

Against this backdrop, the multiple regression method is deemed appropriate. Here, a particular measure of dependent variable is expressed as multiple linear regression model of the set of dependent variables. Thus, we have the following five models:

Model 1: CCT $=\mathrm{a}+\mathrm{b}_{1}$ INR $+\mathrm{b}_{2}$ INA $+\mathrm{b}_{3} \mathrm{RST}+\mathrm{b}_{4} \mathrm{COT}+\mathrm{b}_{5} \mathrm{SUP}+\mathrm{b}_{6} \mathrm{STR}+\mathrm{b}_{7} \mathrm{BEN}$

Model 2: CIV $=a+b_{1}$ INR $+b_{2}$ INA $+b_{3}$ RST $+b_{4}$ COT $+b_{5}$ SUP $+b_{6}$ STR $+b_{7}$ BEN

Model 3: COU $=\mathrm{a}+\mathrm{b}_{1} \mathrm{INR}+\mathrm{b}_{2} \mathrm{INA}+\mathrm{b}_{3} \mathrm{RST}+\mathrm{b}_{4} \mathrm{COT}+\mathrm{b}_{5} \mathrm{SUP}+\mathrm{b}_{6} \mathrm{STR}+\mathrm{b}_{7}$ BEN

Model 4: SPM $=\mathrm{a}+\mathrm{b}_{1}$ INR $+\mathrm{b}_{2}$ INA $+\mathrm{b}_{3}$ RST $+\mathrm{b}_{4}$ COT $+\mathrm{b}_{5} \mathrm{SUP}+\mathrm{b}_{6} \mathrm{STR}+\mathrm{b}_{7}$ BEN

Model 5: ALT $=\mathrm{a}+\mathrm{b}_{1}$ INR $+\mathrm{b}_{2}$ INA $+\mathrm{b}_{3} \mathrm{RST}+\mathrm{b}_{4} \mathrm{COT}+\mathrm{b}_{5} \mathrm{SUP}+\mathrm{b}_{6} \mathrm{STR}+\mathrm{b}_{7}$ BEN

Where

$\mathrm{CCT}=$ Conscientiousness

CIV = Civic Virtue

$\mathrm{COU}=$ Courtesy

SPM $=$ Sportsmanship

ALT $=$ Altruism

INR = Individual Responsibility

INA = Individual Autonomy

RST $=$ Risk Tolerance

COT $=$ Conflict Tolerance

SUP $=$ Support

$\mathrm{STR}=$ Structure

BEN $=$ Belief \& Norms

$\mathrm{a}, \mathrm{bi}=$ parameters to be estimated in the regression equation, where the b's are the coefficients of the variables.

The decision rule is that if the value of bi is positive and statistically significant then it means that organizational cultural variable can significantly explain employees' citizenship behaviour. The statistical significance of the parameter estimates is determined by comparing the probability values (P-values) of the t-score with $0.05 \%$ level of significance. If $\mathrm{P}$ - value is less than $0.05 \%$ the estimate is significant and the null hypothesis is not accepted (that is rejected)

\section{Results and Discussion}

Table-1. Descriptive characteristic of data collected.

\begin{tabular}{l|c|c|c|c|c|c}
\hline Stats & Mean & Median & Max & Min & Std Dv & N \\
\hline Individual Responsibility (INR) & 3.87 & 4 & 5 & 1 & 0.96 & 253 \\
\hline Conflict Tolerance (COT) & 3.81 & 4 & 5 & 1 & 0.93 & 253 \\
\hline Support (SUP) & 3.89 & 4 & 5 & 1 & 0.83 & 253 \\
\hline Structure (STR) & 3.93 & 4 & 5 & 1 & 0.93 & 253 \\
\hline Belief \& Norms (BEN) & 3.81 & 4 & 5 & 1 & 0.83 & 253 \\
\hline Individual Autonomy (INA) & 3.93 & 4 & 5 & 1 & 0.97 & 253 \\
\hline Risk Tolerance (RST) & 3.93 & 4 & 5 & 1 & 0.83 & 253 \\
\hline Courtesy (COU) & 3.86 & 4 & 5 & 1 & 0.97 & 253 \\
\hline Civic Virtue (CIV) & 3.83 & 4 & 5 & 1 & 0.93 & 253 \\
\hline Conscientiousness (CCT) & 3.92 & 4 & 5 & 1 & 0.88 & 253 \\
\hline Altruism (ALT) & 4.13 & 4 & 5 & 2 & 0.86 & 253 \\
\hline Sportsmanship (SPM) & 3.90 & 4 & 5 & 1 & 0.86 & 253 \\
\hline
\end{tabular}




\begin{tabular}{c|c|c|c|c|c|c|c|c|c|c|c|c}
\hline & INR & COT & SUP & STR & BEN & INA & RST & COU & CIV & CCT & ALT & SPM \\
\hline INR & 1 & & & & & & & & & & & \\
\hline COT & 0.50 & 1 & & & & & & & & & & \\
\hline SUP & 0.54 & 0.45 & 1 & & & & & & & & & \\
\hline STR & 0.56 & 0.63 & 0.49 & 1 & & & & & & & & \\
\hline BEN & 0.50 & 0.56 & 0.45 & 0.63 & 1 & & & & & & & \\
\hline INA & 0.54 & 0.51 & 0.63 & 0.57 & 0.51 & 1 & & & & & & \\
\hline RST & 0.53 & 0.42 & 0.56 & 0.48 & 0.42 & 0.60 & 1 & & & & & \\
\hline COU & 0.65 & 0.59 & 0.63 & 0.66 & 0.59 & 0.68 & 0.62 & 1 & & & & \\
\hline CIV & 0.66 & 0.60 & 0.63 & 0.62 & 0.60 & 0.66 & 0.62 & 0.67 & 1 & & & \\
\hline CCT & 0.61 & 0.35 & 0.41 & 0.40 & 0.35 & 0.43 & 0.39 & 0.52 & 0.57 & 1 & & \\
\hline ALT & 0.36 & 0.45 & 0.32 & 0.49 & 0.65 & 0.38 & 0.30 & 0.48 & 0.55 & 0.37 & 1 & \\
\hline SPM & 0.38 & 0.30 & 0.69 & 0.32 & 0.30 & 0.63 & 0.75 & 0.47 & 0.46 & 0.53 & 0.30 & 1 \\
\hline
\end{tabular}

The above table shows that all the studied variables are positively correlated and thus conformable for regression test.

Table-3. Normality test.

\begin{tabular}{c|c|c|c|c|c}
\hline Variable & Obs & Pr (skewness) & Pr (kurtosis) & Adj chi2(2) & Prob>chi2 \\
\hline INR & 253 & 0.0000 & 0.293 & 30.24 & 0.0000 \\
\hline COT & 253 & 0.0000 & 0.2900 & 21.24 & 0.0000 \\
\hline SUP & 253 & 0.0000 & 0.0027 & 36.29 & 0.0000 \\
\hline STR & 253 & 0.0000 & 0.0016 & 35.92 & 0.0000 \\
\hline BEN & 253 & 0.0000 & 0.2900 & 21.24 & 0.0000 \\
\hline INA & 253 & 0.0000 & 0.0161 & 29.36 & 0.0000 \\
\hline RST & 253 & 0.0000 & 0.0016 & 35.92 & 0.0000 \\
\hline COU & 253 & 0.0000 & 0.0366 & 30.13 & 0.0000 \\
\hline CIV & 253 & 0.0000 & 0.1141 & 24.39 & 0.0000 \\
\hline CCT & 253 & 0.0000 & 0.0097 & 31.39 & 0.0000 \\
\hline ALT & 253 & 0.0000 & 0.2439 & 23.77 & 0.0000 \\
\hline SPM & 253 & 0.0000 & 0.0251 & 27.56 & 0.0000 \\
\hline
\end{tabular}

The above test for normality indicates that all the variables are normally distributed and suitable for regression analysis.

Table-4. Post Regression Analysis for hypothesis testing.

\begin{tabular}{l|c}
\hline VIF Test (Mean) & 2.19 \\
\hline Heteroskedasticity & $1.96(0.1616)$ \\
\hline Ramsey RESET test & $3.46(0.1175)$ \\
\hline Observation & 253 \\
\hline
\end{tabular}

The above test shows that the variation between the dependent and independent variables are homoscedastic that is, there is no heteroscedasticity problem at $1.96(0.1616)$. Therefore, the regression results can be used to test the formulated hypotheses. The test for variance inflation factor, the mean VIF value is 2.19 which is less than the benchmark value of 10 indicates the absence of multicollinearity. Similarly, the result of Ramsey regression equation specification error test, with the probability value of 0.1175 , is an affirmation that the model has no omitted variables.

\subsection{Test of Hypotheses \\ 4.1.1. Hypothesis One}

Ho:: Organizational culture does not significantly predicts employees' conscientiousness

Table-5. OLS regression result of organizational culture and employee conscientiousness.

\begin{tabular}{|c|c|c|c|c|}
\hline Variables. & Coef. & Std. Err. & $\mathbf{T}$ & $\mathrm{P}>/ \mathrm{t} /$ \\
\hline Individual Responsibility (INR) & .3335 & .0452 & 7.36 & 0.000 \\
\hline Conflict Tolerance (COT) & .2481 & .0492 & 5.04 & 0.000 \\
\hline Support (SUP) & .3076 & .0556 & 5.53 & 0.000 \\
\hline Structure (STR) & .1391 & .0553 & 2.52 & 0.013 \\
\hline Belief \& Norms (BEN) & .1756 & .0499 & 3.52 & 0.001 \\
\hline Individual Autonomy (INA) & .2903 & .0554 & 5.23 & 0.000 \\
\hline Risk Tolerance (RST) & .1140 & .0382 & 2.98 & 0.003 \\
\hline Cons. & -.5710 & .1982 & -2.88 & 0.004 \\
\hline R-squared & \multicolumn{4}{|c|}{0.7229} \\
\hline Adj. R-squared: & \multicolumn{4}{|c|}{0.6941} \\
\hline $\mathrm{F}$ & \multicolumn{4}{|c|}{91.29} \\
\hline Prob. $>\mathrm{F}$. & \multicolumn{4}{|c|}{0.000 . } \\
\hline
\end{tabular}

The regression result as per above table, shows Adjusted R-squared of 0.71 , explaining about $71.49 \%$ systematic variation in employees' conscientiousness, thus signaling that all the dimensions of organizational culture significantly predict employees' conscientiousness in the Broadcast organizations. The positive coefficient values $(\mathrm{INR}=0.3335, \mathrm{COT}=0.2482, \mathrm{SUP}=0.3076, \mathrm{STR}=0.1391, \mathrm{BEN}=0.1757, \mathrm{INA}=0.2903$ and $\mathrm{RST}$ 
$=0.1140$ ) show that a unit change in organizational cultural dimensions, will lead to $33.3 \%, 24.8 \%, 30.8 \%, 13.9 \%$, $17.6 \%, 29 \%$, and $11.4 \%$ variations respectively in employees' conscientiousness. The t-value of the regression result for employees' conscientiousness pass the threshold of $5 \%$ significance level. By this result, we accept the alternate hypothesis that organizational culture significantly predicts employees' conscientiousness.

\subsubsection{Hypothesis Tro}

$\mathrm{Ho}_{2}$ : Organizational culture does not significantly predicts employees' civic virtue.

Table-6. OLS regression result of organizational culture and civic virtue.

\begin{tabular}{|c|c|c|c|c|}
\hline Variables. & Coef. & Std. Err. & $\mathbf{T}$ & $\mathbf{P}>/ \mathrm{t} /$ \\
\hline Individual Responsibility (INR) & .2429 & .0487 & 4.98 & 0.000 \\
\hline Conflict Tolerance (COT) & .2481 & .0492 & 5.04 & 0.000 \\
\hline Support (SUP) & .3076 & .0556 & 5.53 & 0.000 \\
\hline Structure (STR) & .1201 & .0391 & 3.07 & 0.002 \\
\hline Belief \& Norms (BEN) & .1706 & .0538 & 3.17 & 0.002 \\
\hline Individual Autonomy (INA) & .4442 & .0597 & 7.44 & 0.000 \\
\hline Risk Tolerance (RST) & .0902 & .0412 & 2.19 & 0.029 \\
\hline Cons. & -.1789 & .2135 & -0.84 & 0.403 \\
\hline R-squared & \multicolumn{4}{|c|}{0.659} \\
\hline Adj. R-squared: & \multicolumn{4}{|c|}{0.650} \\
\hline $\mathrm{F}$ & \multicolumn{4}{|c|}{67.89} \\
\hline Prob.>F. & \multicolumn{4}{|c|}{0.000.} \\
\hline
\end{tabular}

The result as per above table, reflects Adjusted R-squared of 0.6598 , explaining about $65.98 \%$ systematic variation in employees' civic virtue, evidencce that dimensions of organizational culture significantly predict employees' civic virtue in Broadcast organizations in Nigeria. The positive coefficient values for individual responsibility $(\mathrm{INR})=0.243$, conflict tolerance $(\mathrm{CT})=0.248$, support $(\mathrm{SUP})=0.307$, structure $(\mathrm{STR})=0.120$, belief and norms $(\mathrm{BEN})=0.171$, individual autonomy $(\mathrm{INA})=0.444$, and risk tolerance $(\mathrm{RST})=0.90$, suggest that the dimensions of organizational culture, explains about $24.3 \%, 24.8 \%, 30.8 \%, 12 \%, 17.1 \%, 44.4 \%$, and $0.9 \%$, of the systematic variations in employees' civic virtue of the sampled broadcasting organizations. The t-values of the regression result for employees' civic virtue fall within $5 \%$ threshold or $95 \%$ confidence level - a strong affirmation that organizational culture significantly predicts employees' civic virtue.

\subsubsection{Hypothesis Three}

Hos: Organizational culture does not significantly impact on employees' courtesy.

\begin{tabular}{l|c|c|c|c}
\multicolumn{5}{c}{ Table-7. OLS regression result of organizational culture and employee courtesy. } \\
\hline Variables. & Coef. & Std. Err. & T & P>/t/ \\
\hline Individual Responsibility (INR) & .2238 & .0549 & 4.07 & 0.000 \\
\hline Conflict Tolerance (COT) & .2189 & .0560 & 3.90 & 0.000 \\
\hline Support (SUP) & .3774 & .0634 & 5.95 & 0.000 \\
\hline Structure (STR) & .0957 & .0446 & 2.14 & 0.033 \\
\hline Belief \& Norms (BEN) & .3114 & .0606 & 5.14 & 0.000 \\
\hline Individual Autonomy (INA) & .3063 & .0672 & 4.55 & 0.000 \\
\hline Risk Tolerance (RST) & .0730 & .0464 & 1.57 & 0.117 \\
\hline Cons. & .0100 & .2405 & 0.04 & 0.967 \\
\hline R-squared & \multicolumn{5}{|c}{0.589} \\
\hline Adj. R-squared: & \multicolumn{5}{|l}{0.578} \\
\hline F & \multicolumn{5}{|c}{0.000} \\
\hline Prob.>F. F.
\end{tabular}

The positive coefficient values for Individual Responsibility $(\mathrm{INR})=0.223$, Conflict Tolerance $(\mathrm{CT})=0.218$, Support $(\mathrm{SUP})=0.377$, Structure $(\mathrm{STR})=0.095$, Belief \& Norms $(\mathrm{BEN})=0.311$, Individual Autonomy $($ INA $)=$ $0.306, \&$ Risk Tolerance $(\mathrm{RST})=0.073$, illustrate that, dimensions of organizational culture, explain about $22.3 \%$, $21.8 \%, 37.7 \%, 95.7 \%, 31.1 \%, 30.6 \%, 7.3 \%$, of the systematic variations in employees' civic virtue. Similarly, the Adjusted R-squared of 0.5780 , is equivalent to about $57.8 \%$ systematic variation in employees' civic virtue, implying that dimensions of organizational culture significantly predict employees' civic virtue in Nigerian Broadcast organizations. Again, the t-values for employees' civic virtue are observed to pass the $5 \%$ significance level, thus affirming organizational culture significantly predicting employees' civic virtue.

\subsubsection{Hypothesis Four}

Ho: Organizational culture does not significantly predicts employees' sportsmanship. 


\begin{tabular}{|c|c|c|c|c|}
\hline Variables. & Coef. & Std. Err. & $\mathbf{T}$ & $\mathrm{P}>/ \mathrm{t} /$ \\
\hline Individual Responsibility (INR) & .3335 & .0452 & 7.36 & 0.000 \\
\hline Conflict Tolerance (COT) & .3774 & .0634 & 5.95 & 0.000 \\
\hline Support (SUP) & .0957 & .0446 & 2.14 & 0.033 \\
\hline Structure (STR) & .1391 & .0553 & 2.52 & 0.013 \\
\hline Belief \& Norms (BEN) & .1756 & .0499 & 3.52 & 0.001 \\
\hline Individual Autonomy (INA) & .2903 & .0554 & 5.23 & 0.000 \\
\hline Risk Tolerance (RST) & .1140 & .0382 & 2.98 & 0.003 \\
\hline Cons. & -.5710 & .1982 & -2.88 & 0.004 \\
\hline R-squared & \multicolumn{4}{|c|}{0.722} \\
\hline Adj. R-squared: & \multicolumn{4}{|c|}{0.714} \\
\hline $\mathrm{F}$ & \multicolumn{4}{|c|}{91.29} \\
\hline Prob. $>$ F. & \multicolumn{4}{|c|}{0.000} \\
\hline
\end{tabular}

The regression coefficients for Individual Responsibility $(\mathrm{INR})=0.333$, Conflict Tolerance $(\mathrm{CT})=0.377$, Support $(\mathrm{SUP})=0.096$, Structure $(\mathrm{STR})=0.139$, Belief \& Norms $(\mathrm{BEN})=0.1756$ Individual Autonomy $($ INA $)=$ 0.290 , \& Risk Tolerance $(\mathrm{RST})=0.144$, indicate that all dimensions of organizational culture, explain about $33.3 \%, 37.7 \%, 9.57 \%, 13.9 \%, 17.6 \%, 29 \%$, \& $11.4 \%$, of the systematic variations in employees' sportsmanship. Similarly, the Adjusted R-squared of 0.7149 , is equivalent to about $71.49 \%$ of systematic variation in employees' sportsmanship, suggesting that dimensions of organizational culture significantly predict employees' sportsmanship. In the same vein, the corresponding t-values are also seen to pass the $5 \%$ significance level, meaning that organizational culture significantly predicting employees' sportsmanship.

\subsubsection{Hypothesis Five}

Ho:: Organizational culture does not significantly impact on employees' altruism.

Table-9. OLS regression result of organizational culture and employee altruism.

\begin{tabular}{|c|c|c|c|c|}
\hline Variables. & Coef. & Std. Err. & $\mathbf{T}$ & $\mathrm{P}>/ \mathrm{t} /$ \\
\hline Individual Responsibility (INR) & .2847 & .0419 & 6.78 & 0.000 \\
\hline Conflict Tolerance (COT) & .1804 & .0533 & 3.84 & 0.001 \\
\hline Support (SUP) & .2256 & .0603 & 3.74 & 0.000 \\
\hline Structure (STR) & .0955 & .0424 & 2.25 & 0.026 \\
\hline Belief \& Norms (BEN) & .2419 & .0462 & 5.23 & 0.000 \\
\hline Individual Autonomy (INA) & .3642 & .0514 & 7.09 & 0.000 \\
\hline Risk Tolerance (RST) & .1341 & .0354 & 3.78 & 0.000 \\
\hline Cons. & -.5498 & .1837 & -2.99 & 0.003 \\
\hline R-squared & \multicolumn{4}{|c|}{0.748} \\
\hline Adj. R-squared: & \multicolumn{4}{|c|}{0.741} \\
\hline $\mathrm{F}$ & \multicolumn{4}{|c|}{104.04} \\
\hline Prob. $>$ F. & \multicolumn{4}{|c|}{0.000} \\
\hline
\end{tabular}

Note: Dependent Variable: Employee Altruism.

Note:

CCT $=$ Conscientiousness

CIV = Civic Virtue

$\mathrm{COU}=$ Courtesy

$\mathrm{SPM}=$ Sportsmanship

$\mathrm{ALT}=$ Altruism

INR = Individual Responsibility

INA $=$ Individual Autonomy

$\mathrm{RST}=$ Risk Tolerance

$\mathrm{COT}=$ Conflict Tolerance

SUP $=$ Support

$\mathrm{STR}=$ Structure

BEN = Belief \& Norms

The positive regression coefficients: (Individual Responsibility $(\mathrm{INR})=0.285$, Conflict Tolerance $(\mathrm{CT})=$ 0.180, Support $(\mathrm{SUP})=0.226$, Structure $(\mathrm{STR})=0.956$, Belief \& Norms $(\mathrm{BEN})=0.242$, Individual Autonomy $($ INA $)=0.364, \&$ Risk Tolerance $($ RST $)=0.134)$, foreclose that organizational culture dimensions, explain about $28.5 \%, 18 \%, 22.6 \%, 95.6 \%, 24.2 \%, 36.4 \%$, and $13.4 \%$ of the systematic changes in employees' altruism. The Adjusted R-squared of 0.7411 which represents about $74.11 \%$ of systematic variation in employees' sportsmanship, implies that dimensions of organizational culture significantly predict employees' altruism. The corresponding tvalues are also seen to satisfy the $95 \%$ confidence level, evidence that organizational culture significantly predicts employees' altruism.

\section{Conclusion}

There are evidences of wide spread conformity and acceptance in organizations that culture is obvious and that it exists, and as such has positive influence on citizenship behavioral variables. It is therefore important to state that citizenship behaviour features in these organizations is a function of good healthy organizational cultural practices, which every employee working in that organization holds with high regard. Results have also identified good reward system as an antidote to designing and implementing sound organizational culture in the Nigerian broadcast organizations and in diaspora. It stands to reason therefore that positive organizational cultural atmosphere evolves an environment where citizenship behaviour is guaranteed, and where the employees are willing and ready to deliver quality services with great commitment. In Nigeria contextual literature, we have been made to understand that since the policy of deregulation of the broadcast sector in 1992 was carried out, 
employees' behaviour (public and private combined) in the broadcast industry has not been appraised in line with the diverse cultures of their respective organizations. This is one of the gaps this study intends to bridge. We argued succinctly based on our findings that all the dimensions of organizational culture significantly and positively predict the employees' citizenship behavior in the Nigerian broadcasting industry. The implications of this for managers/organizations are: a workable structure that aligns the needs of the employees with those of the management will help to breed, nurture, and retain loyal, committed and energetic employees; while a weak or bureaucratic structure that neglect the plights of the employees will end up harvesting and breeding group of dissident, idiosyncratic, vindictive, and shoddy workers.

\section{Recommendations}

1. Management should be concerned with evolving behaviours geared towards yielding significant higher results in the very long term than in the short term. This can be partly accomplished in its sincere effort to establish individual level behaviour related appraisal ratings and allocation of rewards among employees in the organization.

2. Management should make their employees' to be more committed to culture that will eventually transcend to employees' sense of belonging and self-identity in their roles as organisational citizen and stakeholders.

3. Management should evolve a system that will help discern employees with good citizenship behavior.

4. The most effective and influential elements within the components of employees' citizenship behaviour should be re-emphasized by management in a polite and considerable manner as this can further enhance such behaviours. In this way, mechanism to improving the productivity of both staff and workers should be put in place.

\section{References}

Appelbaum, S. (2004). Organizational citizenship behavior: A case study of culture, leadership and trust. Management Decision, 42(1), 13-40. Arabaci, I. B. (2010). The effects of depersonalization and organizational cynicism levels on the job satisfaction of educational inspectors African Journal of Business Management, 4(13), 2802-2811.

Aslam, R. (2012). Investigating the relationship of ocb with job satisfaction organizational commitment and turnover intensions. International Journal of Economics and Management Sciences, 1(9), 90-100.

Beck, K., \& Wilson, C. (2000). Development of affective organizational commitment: A cross-sequential examination of change with tenure. Journal of Vocational Behavior, 56(1), 114-136.Available at: https://doi.org/10.1006/jvbe.1999.1712.

Chamdan, P. (2013). Influence analysis of organizational culture organizational commitment job and satisfaction organizational citizenship behavior (OCB) toward improved organizational performance. International Journal of Business, Humanities and Technology, 3(5), 86100 .

Denison, D. R. (2000). Organizational culture: Can it be a key lever for driving organizational change. Cited in S. Cartwright, E C. Cooper (Eds.), the handbook of organizational culture. John Wiley \& Sons: London.

Erhan, K., \& Hatice, U. (2014). Investigation of organizational citizenship behavior, organizational silence and employee performance at physicians and nurses, and the relationship among them. Business Management Dynamics, 3(11), 25-34.

Falemu, A., \& Ojo, J. (2013). Organizational culture, job satisfaction and commitment of Lagos-based construction workers. Journal of Business and Management, 13(6), 108-120.Available at: https://doi.org/10.9790/487x-136108120.

Gim, G., \& Desa, N. M. (2014). The impact of distributive justice, procedural justice, and affective commitment on turnover intention among public and private sector employees in Malaysia. International Journal of Social Science and Humanity, 4(6), 487492.Available at: https://doi.org/10.7763/ijssh.2014.v4.404.

Guillard, P.-D., \& Neweś, G.-A. (2010). Positive organizational potential, organizational commitment and organizational citizenship behaviour: A French/Polish comparison. Journal of Positive Management, 1(1), 47-64.Available at: https://doi.org/10.12775/jpm.2010.004.

Gülsevim, G. Y. (2017). The relationship among perceived organizational support, job satisfaction, and alienation: An empirical study on academicians. International Journal of Business and Social Science, 8(1), 96-106.

Hameed, A., Ramzan, M., \& Zubair, H. M. K. (2014). Impact of compensation on employee performance (empirical evidence from banking sector of Pakistan). International Journal of Business and Social Science, 5(2), 302-309.

Homans, G. C. (1958). Social behavior as exchange. American Journal of Sociology, 63(6), 597-606.

Khan, S. K., \& Rashid, M. Z. A. (2012). The mediating effect of organizational commitment in the organizational culture, leadership and organizational justice relationship with organizational citizenship behavior: A study of academicians in private higher learning institutions in Malaysia. International Journal of Business and Social Science, 3(8).

Kroth, M., \& Peutz, J. (2011). Workplace issues in Extension-A delphi study of Extension educators. Journal of Extension, 49(1), 1-10.

Mahin, A., \& Mohammad, B. G. (2014). Perceived organizational support, organizational commitment and organizational citizenship behavior among faculty members. Journal of Basic and Applied Scientific Research, 4(7), 231- 235.

Mohanty, J., \& Rath, B. P. (2012). Influence of organizational culture on organizational citizenship behavior: A three-sector study. Global Journal of Business Research, 6(1), 65-76.

Obinozie, R. O. (2016). Effects of management control systems and strategy on performance of minority-owned businesses. Walden University Dissertation and Doctoral Studies.

Organ, D. W. (1997). Organizational citizenship behavior: It's construct clean-up time. Human Performance, 10(2), 85-97.Available at: https://doi.org/10.1207/s15327043hup1002_2.

Organ, D. W., \& Ryan, K. (1995). A meta-analytic review of attitudinal and dispositional predictors of organizational citizenship behavior Personnel Psychology, 48(4), 775-802.Available at: https://doi.org/10.1111/j.1744-6570.1995.tbo1781.x.

Shein, E. H. (1996). Culture the missing concept in organization studies. Administrative Science Quarterly, 41(2), $229-240$.

Tahura, T. D., \& Mehrali, H. (2015). Organizational support in relation to organizational citizenship behaviour in physical education teachers. Indian journal of Fundamental and Applied Life Sciences, 5(2), $1106-1110$.

Tansley, C. (2007). Talent: Strategy, management, measurement. London: Chartered Institute of Personnel and Development.

Valentino, C. L., \& Brunelle, F. W. H. (2004). The role of middle managers in the transmission and integration of organizational culture. Journal of Healthcare Management, 49(6), 393-404

Yamane, T. (1967). Statistics: An introduction analysis (2nd ed.). Harper and Row SciEP. 
Appendix A

Table-A1. Test for reliability.

\begin{tabular}{c|c|c|c|c|c|c}
\hline Item & Obs & Sign & $\begin{array}{c}\text { Item-test } \\
\text { correction }\end{array}$ & $\begin{array}{c}\text { Item-rest } \\
\text { correction }\end{array}$ & $\begin{array}{c}\text { Average inter } \\
\text { item covariance }\end{array}$ & Alpha \\
\hline inr & 20 & + & 0.9069 & 0.8870 & .6814354 & 0.9499 \\
\hline cot & 20 & + & 0.7938 & 0.7571 & .7123445 & 0.9538 \\
\hline sup & 20 & + & 0.8816 & 0.8511 & .6622967 & 0.9509 \\
\hline str & 20 & + & 0.6055 & 0.5378 & .7372249 & 0.9599 \\
\hline ben & 20 & + & 0.7938 & 0.7517 & .7123445 & 0.9538 \\
\hline ina & 20 & + & 0.8707 & 0.8351 & .6556938 & 0.9518 \\
\hline rst & 20 & + & 0.6055 & 0.5378 & .7372249 & 0.9599 \\
\hline cou & 20 & + & 0.8988 & 0.8738 & .6652632 & 0.9501 \\
\hline civ & 20 & + & 0.8335 & 0.7957 & .6833493 & 0.9526 \\
\hline cct & 20 & + & 0.8822 & 0.8559 & .6795215 & 0.9507 \\
\hline alt & 20 & + & 0.9297 & 0.9146 & .6786603 & 0.9492 \\
\hline spm & 20 & + & 0.9381 & 0.9281 & .7094737 & 0.9507 \\
\hline Test scale & & & & & .6929027 & 0.9566 \\
\hline
\end{tabular}

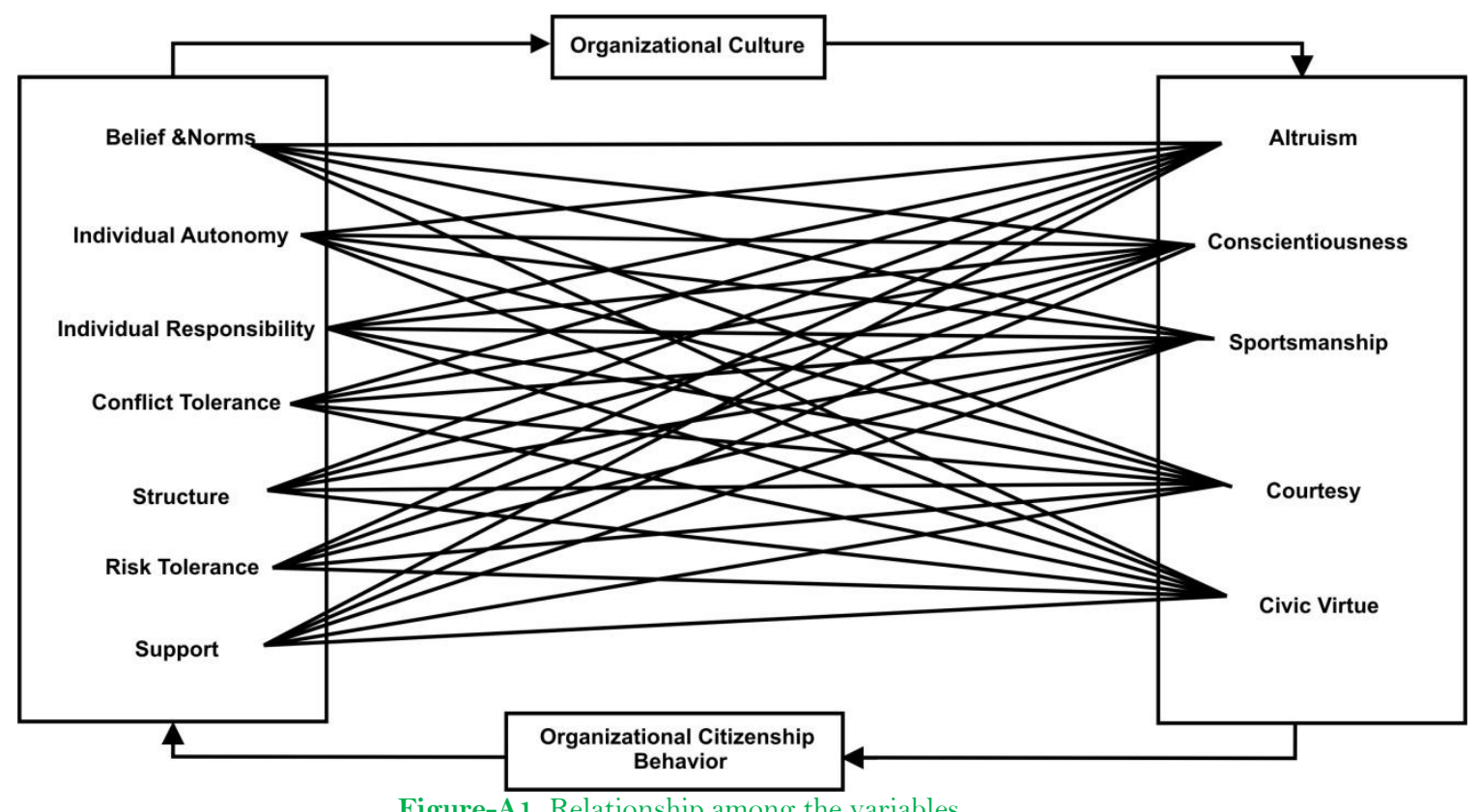

Source: Adapted from Mohanty and Rath (2012). 